\title{
Editorial: Public Will, Activism and Climate Change
}

\author{
John Cook ${ }^{1 *}$, John Kotcher ${ }^{1}$, Neil Stenhouse ${ }^{2}$ and Ed Maibach ${ }^{1}$ \\ ${ }^{1}$ Center for Climate Change Communication, George Mason University, Fairfax, VA, United States, ${ }^{2}$ Greenberg Quinlan \\ Rosner Research, Washington, DC, United States
}

Keywords: climate change communication, environmental activism, consumer activism, public will, strategic communication

\section{Editorial on the Research Topic}

\section{Public Will, Activism and Climate Change}

OPEN ACCESS

Edited by:

Dara M. Wald,

lowa State University, United States

Reviewed by:

Winnifred R. Louis,

University of Queensland, Australia

${ }^{*}$ Correspondence:

John Cook

jcook20@gmu.edu

Specialty section:

This article was submitted to

Science and Environmental

Communication

a section of the journal

Frontiers in Communication

Received: 16 August 2019 Accepted: 12 November 2019 Published: 29 November 2019

Citation:

Cook J, Kotcher J, Stenhouse N and Maibach E (2019) Editorial: Public Will, Activism and Climate Change.

Front. Commun. 4:72.

doi: $10.3389 / f c o m m .2019 .00072$
The temperature goals set in the Paris climate accord are likely to become unattainable if global emissions of greenhouse gases continue to rise after 2020, according to a June 2017 commentary published in Nature by some of the world's leading authorities. To avoid the most serious impacts of climate change, the global community must dramatically reduce its use of fossil fuels within the very near future.

While individual behavior changes can reduce emissions, their contributions are insufficient in the absence of large-scale, systemic change. For emissions to rapidly fall, the policies, regulations, and technologies that shape our energy use must change in ways that promote sustainable lifestyles and remove existing barriers to sustainable actions. These changes are more likely to be made if citizens and consumers demand them. Thus, collective action by citizens and consumers is sorely needed to prod legislators and corporations into enacting the policies and practices that can stabilize the climate.

A majority of Americans-and people in many other nations-tell pollsters they are concerned about climate change and support mitigation policies, but this support has yet to develop into a social movement with sufficient momentum to move mitigation to the top of the political agenda. Over half of Americans believed global warming should be a high priority for the Congress and president in May 2017, but only 12 percent had actually contacted a legislator in support of mitigation policies over the prior year.

There are signs that activism may be growing, however. In the 2 weeks following the Nov. 2016 election, 11,000 new monthly donors signed up with the Sierra Club-nine times their previous monthly record - and this surge was shared by other environmental groups, like the Environmental Defense Fund and National Resources Defense Council. Meeting attendance and volunteerism have reached new highs, and the April 2017 climate march drew 200,000 protesters in Washington, D.C., as well as tens of thousands in hundreds of sister marches across the country. More recently, school strikes across the globe led by Greta Thunberg and the growing influence of organizations such as the Sunrise Movement and Extinction Rebellion, indicate growing social and political momentum for climate action.

This growth may reflect political changes in Washington, D.C., but it may also reflect innovation within the climate movement itself. The movement is advancing the field of strategic communication, with communities like the Climate Advocacy Lab that foster collaboration between researchers and advocacy groups; tools like the Yale Climate Opinion Maps that permit national polling data to be downscaled to local and regional levels; and sophisticated targeting that permits advocacy groups to effectively identify potential new members.

In this Research Topic, we explore collective action on climate change and the development of public will. The study of mobilization and collective action is interdisciplinary and draws 
on psychology (Van Zomeren et al., 2008), sociology (Jasper, 1998; van Stekelenburg and Klandermans, 2013), and political science (Tilly, 2001; McAdam, 2017). Following Raile and colleagues' definition of public will as "a social system's shared recognition of a particular problem and resolve to address the situation in a particular way through sustained collective action," we feature papers that elucidate the individual, institutional, and social factors that lead people to become active politically on climate change, as well as the barriers that inhibit them from doing so.

What role do individual factors - anger, hope, efficacy and risk perceptions-play in motivating people to engage in collective climate action, and what inhibits them from doing so? Marlon et al. found that constructive hope and doubts are positively correlated with policy support and political engagement, while false hope and fatalistic doubt has the opposite relationshipindicating that focusing on constructive hope and doubts may help mobilize action on climate change. Geiger and Swim explored how gendered impressions of activists predict interest in engaging in activism. Their results point to a potential "dark side" of appearing masculine: perceptions of negative masculine traits were associated with counter-productive activism intent. Ballew et al. found that Latinos are more likely than Whites to report contacting government official about climate change, with stronger risk perceptions best predicting differences in climate change activism between Latinos and Whites.

What impact do different communication framings have on public attitudes and motivation to engage in climate activism? Velautham et al. showed that communicating the local impacts of sea level rise results is an effective way to motivate acceptance and engagement with the issue of climate change. Bloodhart et al. found that while people say they prefer messages framed without emotion, climate change messages framed with negative emotions are preferred over non-emotional messages.

How does the media cover the issue of climate change, and what role does this play in fostering or inhibiting activism? Stecula and Merkley content analyzed news coverage of climate change in influential media sources such as the New York Times and the Wall Street Journal. They found that frames that reduce support for climate action, such as frames emphasizing uncertainty or potential economic harms of climate mitigation policy, have been on the decline. In another study, Swim

\section{REFERENCES}

Jasper, J. M. (1998). The emotions of protest: affective and reactive emotions in and around social movements. Sociol. Forum 13, 397-424. doi: 10.1023/A:10221753 08081

McAdam, D. (2017). Social movement theory and the prospects for climate change activism in the United States. Annu. Rev. Polit. Sci. 20, 189-208. doi: 10.1146/annurev-polisci-052615-025801

Slater, M. D., and Gleason, L. S. (2012). Contributing to theory and knowledge in quantitative communication science. Commun. Methods Measures 6, 215-236. doi: 10.1080/19312458.2012.732626

Tilly, C. (2001). Mechanisms in political processes. Annu. Rev. Polit. Sci. 4, 21-41. doi: 10.1146/annurev.polisci.4.1.21

van Stekelenburg, J., and Klandermans, B. (2013). The social psychology of protest. Curr. Sociol. 61, 886-905. doi: 10.1177/0011392113 479314 et al. conducted surveys before and after the 2017 March for Science and People's Climate March. They found that collective efficacy beliefs increased after the marches, with the greatest effect among consumers of conservative news sources (consistent with the fact that conservative media dedicated less coverage than liberal news sources to the marches prior to the marches).

Finally, how might research into collective action inform the strategies employed by environmental groups? Han and Barnett-Loro offer a framework for synthesizing research on movement-building that demonstrates ways to build political power, and identifies areas where additional research is needed. They emphasize the importance of more research into the strategic leadership choices and collective contexts that facilitate movement-building in addition to tactics designed to influence public opinion and individual behaviors.

We asked the contributing authors to specifically identify how they feel their research contributes to social science theory about public will and climate change activism, using Slater and Gleason's (2012) framework. The framework includes nine categories of contributions, most of which have subcategories: advancing fundamental conceptual issues; extending a theory's range; elucidating causal mechanisms and contingencies; creating a new theory; describing phenomena and generating hypotheses; or comparing, synthesizing or reviewing theories. We encourage the journal to adopt this approach going forward, as we feel it's helpful to readers and to the field at large when authors are clear about how their scholarship has helped to advance the field.

In conclusion, this Research Topic offers valuable insights into the factors influencing people's willingness to engage in collective action, as well as potential barriers. These findings inform possible ways forward for communicators and organizations seeking to build public will and inspire people to become more politically active. It also provides frameworks for further research into this area.

\section{AUTHOR CONTRIBUTIONS}

JC wrote first draft of editorial. EM, JK, and NS edited draft to produce final draft.

van Zomeren, M., Postmes, T., and Spears, R. (2008). Toward an integrative social identity model of collective action: a quantitative research synthesis of three socio-psychological perspectives. Psychol. Bull. 134:504. doi: 10.1037/0033-2909.134.4.504

Conflict of Interest: The authors declare that the research was conducted in the absence of any commercial or financial relationships that could be construed as a potential conflict of interest.

Copyright (c) 2019 Cook, Kotcher, Stenhouse and Maibach. This is an open-access article distributed under the terms of the Creative Commons Attribution License (CC $B Y)$. The use, distribution or reproduction in other forums is permitted, provided the original author(s) and the copyright owner(s) are credited and that the original publication in this journal is cited, in accordance with accepted academic practice. No use, distribution or reproduction is permitted which does not comply with these terms. 